\title{
Turismo de Base Comunitária (TBC): elementos chaves para aferir seu desempenho na perspectiva da sustentabilidade
}

\section{Community Based Tourism (CBT): key elements to assess its performance in the perspective of sustainability}

\section{Nathália Hallack Fabrino, Helena Araújo Costa, Elimar Pinheiro do Nascimento}

\section{RESUMO}

O turismo de base comunitária (TBC) representa uma proposta de desenvolvimento apoiada na conservação ambiental, na valorização da identidade cultural e na geração de benefícios diretos para as comunidades receptoras. O presente trabaIho, por sua vez, tem como objetivo realizar uma revisão do arcabouço teórico do TBC para, então, identificar os elementos chaves de sua conceituação. A partir da compilação conceitual realizada, foram identificados componentes recorrentes no entendimento do TBC, sob a ótica de diversos atores a ele relacionados: academia, governo, ongs etc. A análise destes componentes possibilitou o delineamento de 6 elementos chaves (dominialidade, interculturalidade, organização social, repartição de benefícios, integração econômica e gestão do bem comum) a serem considerados como base para a construção futura de indicadores capazes de aferir, à luz da sustentabilidade, o desempenho de iniciativas de TBC.

PALAVRAS-CHAVE: Turismo; Base Comunitária; Sustentabilidade; Desempenho.

\section{ABSTRACT}

Community based tourism (CBT) configures a development proposal based on environmental conservation, cultural identity and direct benefit and income flows to locals. This paper aims to conduct a theoretical review of the CBT in order to identify key elements of its different definitions. From the resulted compilation it became possible to identify recurrent components amongst the various understandings from different authors related to it: academia, government, NGOs etc. The identification of these components resulted on the election of 6 key elements, namely: control/property, interculturality, social organization, benefit sharing, economic integration and management of the commons, to be considered within the construction of performance indicators for CBT initiatives from a sustainability point of view.

KEYWORDS: Tourism; Community Based; Sustainability; Performance. 
Turismo de Base Comunitária (TBC): elementos chaves para aferir seu desempenho na perspectiva da sustentabilidade

\section{Introdução}

A reflexão sobre o turismo de base comunitária (TBC) no Brasil, durante muitos anos, trouxe consigo um sentido marginal, periférico, distante da realidade e das tendências políticas públicas nacionais e internacionais. Neste período, poucos profissionais mergulharam no campo de investigação do TBC. Tal realidade perdurou até meados da década de 1990, quando um movimento de pesquisadores de diferentes inserções do país levou essa discussão para o Encontro de Turismo de Base Local (ENTBL). O encontro demonstrou a demanda por fóruns desta natureza e viabilizou a consolidação de redes não formais de pesquisas. O engajamento de pesquisadores em torno do TBC possibilitou o desenvolvimento de pesquisas, projetos e publicações sobre a temática. Esta produção acadêmica, no entanto, permaneceu nos "bastidores" até recentemente (IRVING, 2009).

Para Irving (2009), um novo olhar sob o TBC ocorre a partir da convergência de uma série de fatores surgidos em âmbito nacional e internacional, a saber: (i) a interpretação política do turismo como uma alternativa para a inclusão social; (ii) o fortalecimento de temas como a participação social e a governança democrática; (iii) o reconhecimento do capital social e o compromisso de envolver os atores sociais nas ações empreendidas por projetos internacionais; (iv) a inclusão do turismo nas pautas de ONGs de alcance internacional, associado a temáticas sociais e ambientais; (v) a mudança sutil no perfil dos turistas, agora mais comprometidos com a responsabilidade social e ambiental, (vi) a exigência de novas demandas na seara do planejamento, fruto da constatação de que o desenvolvimento do turismo, por vezes, não favorece as populações locais, contribuindo para a exclusão social; (vii) a emergência dos debates sobre o "turismo e sustentabilidade". Neste sentido, o turismo comunitário, orbitando em torno de tais princípios e compromissos, migra da periferia para o centro das discussões, rompendo as barreiras acadêmicas e penetrando no universo político e publicitário.

O lançamento do Edital 01/2008 pelo Ministério do Turismo (Mtur), voltado para o financiamento específico do turismo comunitário, reflete as ações do poder público federal no apoio de um outro modelo de turismo. A chamada contou com a inscrição de quinhentas propostas de todo Brasil, das quais cinquenta foram selecionadas. Segundo o Mtur (2010), a decisão de apoiar o TBC considerou, pelo lado da oferta, a expansão da gestão da atividade turística sob responsabilidade das comunidades locais, aliado a indicadores que apontam o sucesso de algumas destas experiências. Do ponto de vista da demanda, pesquisas nacionais e internacionais demonstram o interesse crescente dos turistas pela vivência de experiências com culturas diferentes e ambientes preservados, revelando a potencialidade das iniciativas de turismo comunitário no Brasil.

Este trabalho consiste no primeiro passo de uma proposta de pesquisa mais ampla, que tem como objetivo final a construção e aplicação de um instrumento de avaliação capaz de aferir, pela ótica da sustentabilidade, o desempenho de iniciativas de TBC no Brasil. A noção de sustentabilidade, neste caso, é baseada na "gênese" do turismo comunitário, ou seja, nas suas premissas e princípios.

O TBC coaduna com as perspectivas do turismo sustentável, sendo sua construção baseada em princípios e valores éticos. No entanto, embora se reconheça que o turismo comunitário nasce de um ideário diferenciado de desenvolvimento turístico, parte-se 
do pressuposto que isto per si não o torna sustentável. Comumente nos apropriamos do discurso da sustentabilidade com base em julgamentos subjetivos, sem referência a padrões ou critérios específicos.

Clarke (1997) ressalta que o turismo sustentável não é uma característica inerente a qualquer forma ou situação já existente, e sim um objetivo que todas as iniciativas devem se esforçar para alcançar. O autor combate o excesso de rótulos que, por sua vez, estabelecem uma relação simbiótica entre a sustentabilidade e algumas práticas de turismo associadas, muitas vezes, a pequena escala - "small was synonymous with sustainable" (p.226). Neste sentido, defende que o turismo sustentável deve ser interpretado com uma meta para realização e não uma característica inerente a uma determinada prática.

Este artigo, por sua vez, pretende identificar componentes do TBC presentes em seu arcabouço conceitual para, então, propor um conjunto de elementos chaves a serem futuramente detalhados em indicadores.

\section{TBC: definições, premissas, princípios}

Ainda que não haja uma definição amplamente aceita do TBC, as perspectivas teóricas sobre o tema apresentam similaridade de princípios e abrangem dimensões antropológicas, sociológicas, econômicas, políticas, históricas, psicológicas e ambientais. Embora estas iniciativas se apresentem de inúmeras formas, considerando a diversidade e a complexidade das realidades locais, percebe-se, como um elemento comum, a interpretação da comunidade como sujeito de seu próprio avanço, participando da concepção, desenvolvimento e gestão do turismo. Segundo o LTDS (2011, p. 07),

a extensão geográfica e a diversidade de experiências encontradas no país também colaboram para a amplitude conceitual do TBC uma vez que este é usado para tratar de contextos tão diversos e diferentes quanto comunidades urbanas e rurais, podendo estar referido às populações tradicionais ou a amálgamas sociais compostas pelos movimentos migratórios e processos de exclusão socieconômicos, entre outros.

Esta falta de consenso em termos conceituais do turismo comunitário, para o Mtur (2010), resulta da heterogeneidade das experiências, da origem do território e da perspectiva política da organização não governamental, responsável por organizar e viabilizar a experiência. Todavia, o Mtur traça como princípios comuns entre as diversas definições: a autogestão; o associativismo e cooperativismo; a democratização de oportunidades e benefícios; a centralidade da colaboração, parceria e participação; a valorização da cultura local e, principalmente, o protagonismo das comunidades locais na gestão da atividade e/ou na oferta de bens e serviços turísticos, visando à apropriação por parte destas dos benefícios advindos do desenvolvimento da atividade turística.

Na tentativa de ilustrar esta amplitude conceitual, o Quadro 1 reúne algumas terminologias, e seus respectivos conceitos, adotados por diferentes segmentos: algumas experiências emblemáticas nacionais, entes da academia, Ong, governo, redes de TBC etc. 
Turismo de Base Comunitária (TBC): elementos chaves para aferir seu desempenho na perspectiva da sustentabilidade

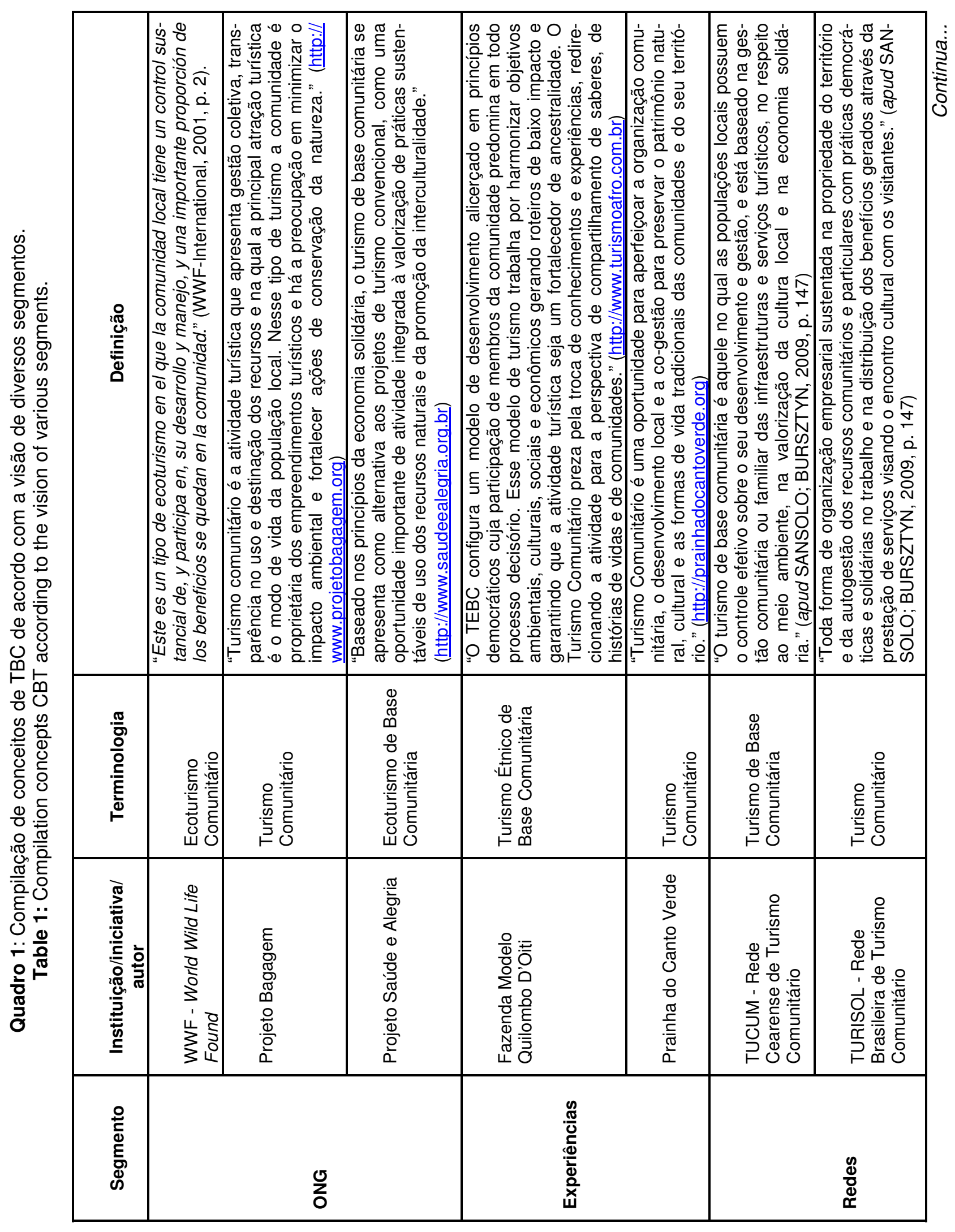

Página 549

Revista Brasileira de Ecoturismo, São Paulo, v.5, n.3, set/dez 2012, pp.546-559. 
Fabrino, N.H.; Costa, H.A.; Nascimento, E.P.

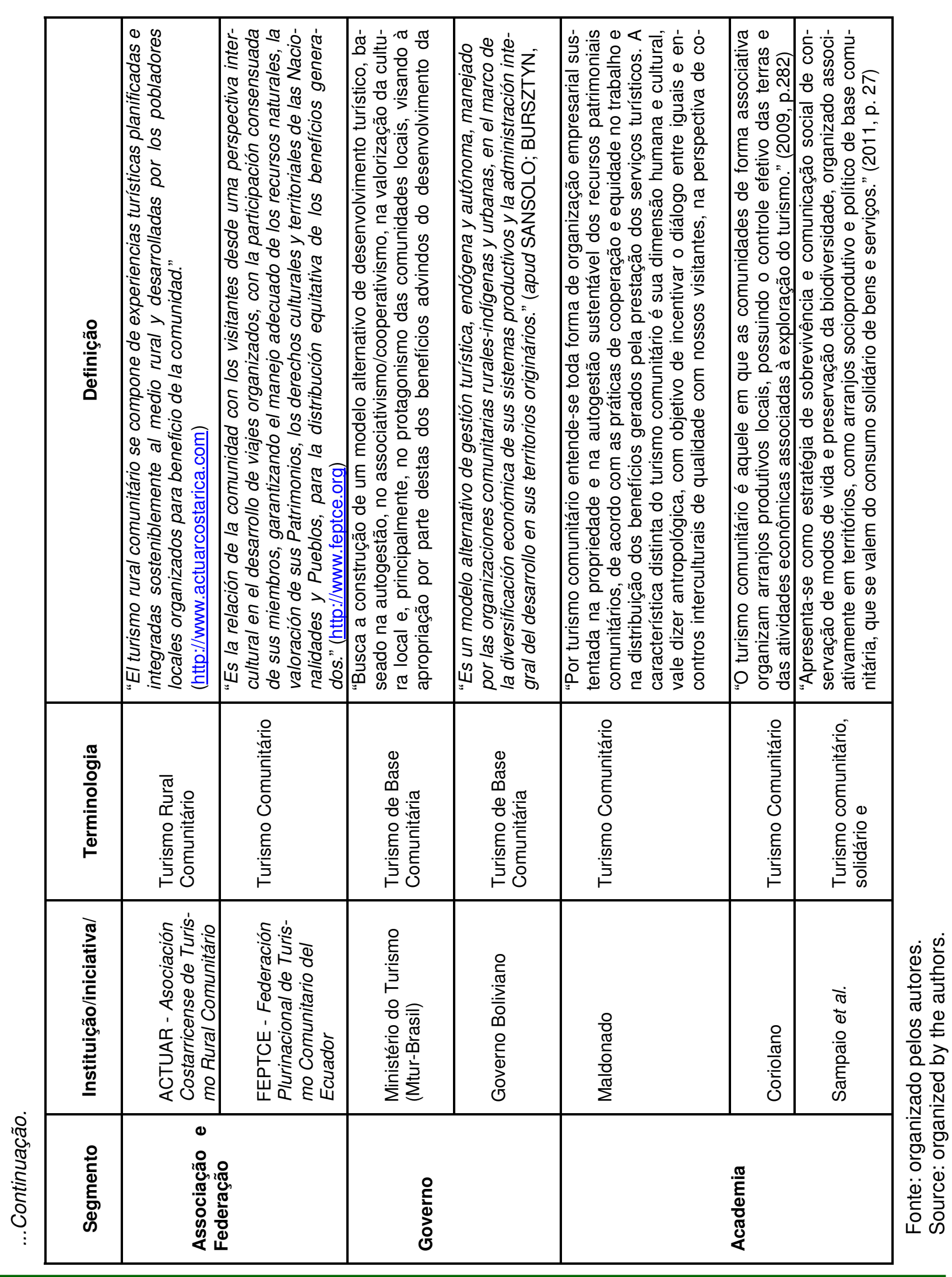

Página 550

Revista Brasileira de Ecoturismo, São Paulo, v.5, n.3, set/dez 2012, pp.546-559. 
Turismo de Base Comunitária (TBC): elementos chaves para aferir seu desempenho na perspectiva da sustentabilidade

Com relação às terminologias apresentadas, nota-se o TBC associado a alguns segmentos do turismo - ecoturismo, turismo rural, turismo étnico. Todavia, é importante ressaltar que o turismo comunitário não representa mais um segmento de mercado, e sim uma proposta de desenvolvimento para o turismo, apoiado em bases endógenas, que pode ser aplicada para diversos segmentos.

A partir deste conjunto de conceitos apresentado no Quadro 01, é possível analisar os componentes comuns que estão presentes na concepção do TBC, conforme o Quadro 2 (pg. 552).

O quadro permite visualizar que o componente mais recorrente na conceituação do TBC, em todos os segmentos, é a noção de organização, gestão e participação comunitária. O componente 01 (Organização/ controle gestão/ participação comunitária) foi citado em praticamente todas as definições, já que o protagonismo da comunidade é o elemento fundamental do turismo comunitário. Parte-se da premissa que os atores sociais comunitários participam de todas as etapas de planejamento e implementação dos projetos. Os atores externos funcionam como indutores do processo, atuando a partir de motivações endógenas. A participação da comunidade e autonomia no processo de decisão, na prática, deve ser analisada de duas perspectivas: interna-externa (o grau de autonomia entre a comunidade com relação ao agente externo) e somente interna (o grau de participação entre os membros da própria comunidade). Esse grau de participação e autonomia não é padrão e pode ocorrer de diferentes formas e intensidades.

Em seguida, a forte presença das dimensões ambiental e cultural ressalta o valor dado pelo TBC às interações entre sociedade e ambiente. Estes componentes, 03 e 04, são os elementos sustentadores da proposta do TBC, ressaltando que os atrativos, serviços e produtos oferecidos estão intimamente associados à relação da comunidade com os seus recursos naturais, suas atividades tradicionais e seus modos de vida. Sampaio et al. (2011), por exemplo, interpretam o TBC como uma proposta institucional que conserva os modos de vida tradicionais e preserva a biodiversidade local. Alinhado a isso, outro ponto destacado em algumas definições relaciona-se com a prática da interculturalidade (componente 07). O TBC parte do princípio de uma relação horizontal entre "quem recebe" e "quem visita", onde o diálogo, a troca e o compartilhamento de vivências são a base desse "encontro".

Ademais, permeando fortemente a noção do TBC está a geração e distribuição de benefícios (componente 2), o que carrega em si a concepção de inclusão e distribuição de ganhos advindos da atividade turística empreendida de modo comunitário.

Também é possível verificar que as questões econômicas estão menos presentes, como que relegadas a um plano secundário, nestas atividades. Nota-se que os aspectos de integração econômica e economia solidária (componentes 5 e 6) são os menos citados nos conceitos, a despeito do fato de um dos princípios do TBC ser a integração do turismo na dinâmica produtiva local, sem substituir as atividades econômicas tradicionais. O desenvolvimento do turismo no âmbito de um arranjo socioprodutivo encontra condições favoráveis, se valendo de sinergias pré-existentes. Tendo 
Fabrino, N.H.; Costa, H.A.; Nascimento, E.P.

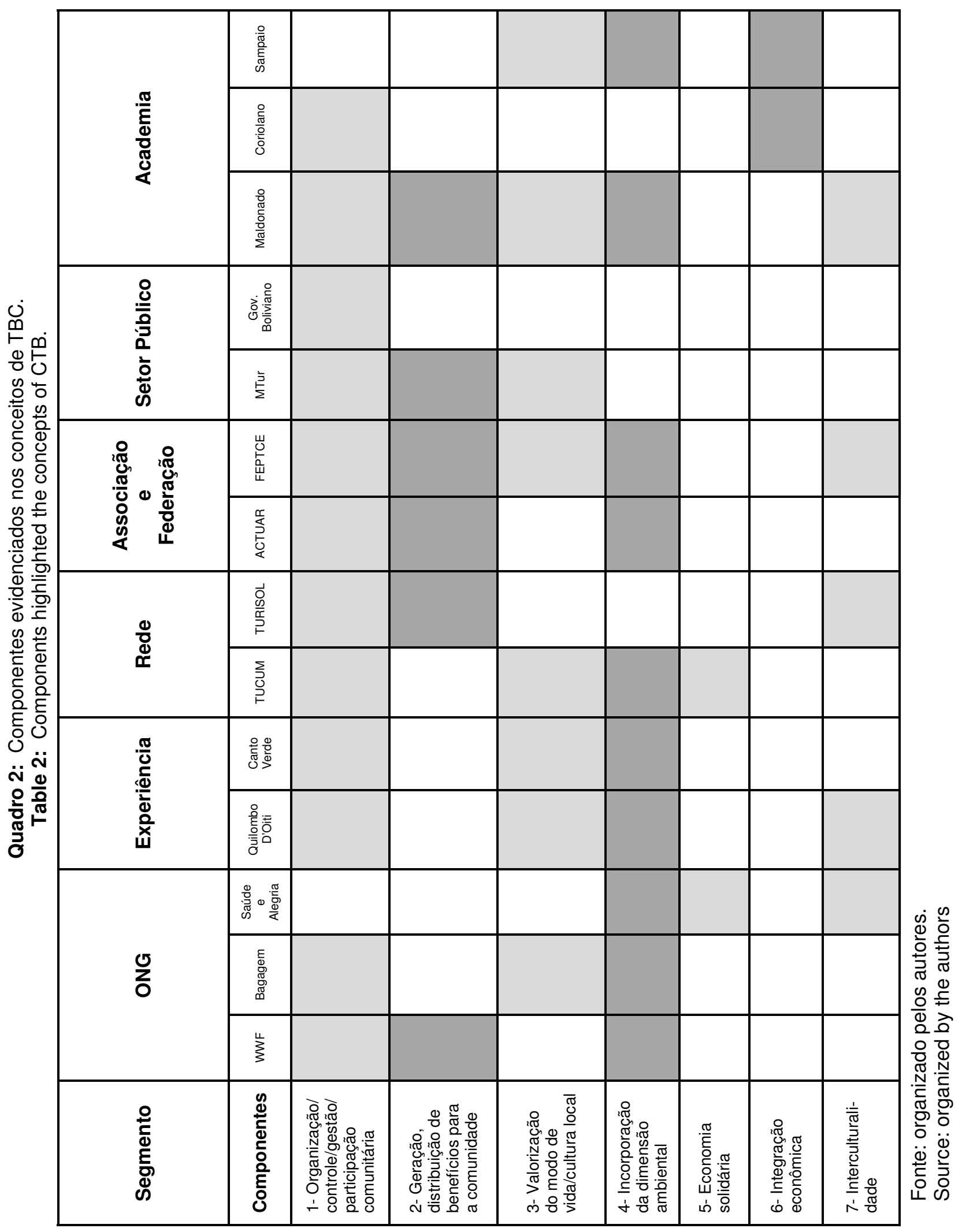

Página 552

Revista Brasileira de Ecoturismo, São Paulo, v.5, n.3, set/dez 2012, pp.546-559. 
Turismo de Base Comunitária (TBC): elementos chaves para aferir seu desempenho na perspectiva da sustentabilidade

como premissa a integração com as demais atividades econômicas de uma dada localidade, o turismo comunitário acaba por propiciar o fortalecimento de atividades tradicionais - pois estas se tornam seus principais atrativos. Estabelece-se, assim, uma relação interdependente que se alimenta positivamente nas duas direções: o turismo encontra nas atividades tradicionais os elementos fundamentais que alicerçam seu desenvolvimento; e as atividades econômicas tradicionais, por sua vez, encontram nas instituições engendradas no turismo um meio para fortalecer as suas próprias práticas, técnicas e modos.

Outros autores, embora não apresentem uma definição fechada para o TBC, discutem em seus trabalhos os princípios, premissas, objetivos e componentes desta proposta. Na definição de Hiwasaki (2006), o turismo comunitário se traduz em quatro objetivos: (i) qualificação e posse, refere-se à participação da comunidade no planejamento e gestão do turismo; (ii) conservação dos recursos, ou seja, o turismo deve impactar positivamente na conservação dos recursos naturais e/ou culturais; (iii) desenvolvimento econômico e social, concerne na geração de benefícios econômicos e sociais para a comunidade local; (iv) qualidade na experiência do visitante, foca no compromisso de assegurar ao visitante uma experiência de qualidade e comprometida com a reponsabilidade social e ambiental.

Segundo Sansolo e Bursztyn (2009), a conservação ambiental, valorização da identidade cultural e geração de benefícios diretos para as comunidades receptoras são os componentes sustentadores desta proposta de turismo. Para os autores, o turismo comunitário não representa apenas mais um segmento do mercado, e sim a possibilidade de um novo paradigma para o turismo. O potencial da atividade não se restringe aos benefícios econômicos, pois contribui para o processo de revalorização da identidade cultural e para a manutenção do modo de vida das populações tradicionais.

Bursztyn et al. (2009, p. 86) destacam que o turismo de base comunitária se contrapõe ao turismo massificado, "requerendo menor densidade de infra-estrutura $e$ serviços e buscando valorizar uma vinculação situada nos ambientes naturais e na cultura de cada lugar". E, reforçam, ainda, como característica central do TBC a estruturação e o estabelecimento de uma relação dialogal entre visitantes e visitados. "Nesse modo relacional, nem os anfitriões são submissos aos turistas, nem os turistas fazem dos hospedeiros meros objetos de instrumentalização consumista" (Ibid).

Irving (2009), por sua vez, defende que o desenvolvimento do turismo comunitário só poderá ocorrer se os protagonistas dos destinos forem sujeitos e não objetos do processo. Na tentativa de se delinear uma conceituação para o turismo comunitário, a autora apresenta algumas premissas que emergem como elementos centrais desta atividade:

(i) Base endógena da iniciativa e desenvolvimento local. O turismo comunitário resulta de uma demanda direta dos grupos sociais que residem no lugar turístico e que estabelecem com este território uma relação cotidiana de dependência material e simbólica. O protagonismo social - resultante do sentimento de pertencimento e do 
poder de influência sobre o processo de decisão - assume uma condição essencial para este tipo de turismo.

(ii) Participação e protagonismo social no planejamento, implementação e avaliação de projetos turísticos. Quanto maior o envolvimento local e as estratégias de participação social no planejamento e implementação dos projetos, mais evidentes são os níveis de protagonismo social e a sustentabilidade das iniciativas.

(iii) Escala limitada e impactos sociais e ambientais controlados. Parte-se da premissa que o turismo comunitário se desenvolva em escala limitada, definida a partir dos recursos locais. O processo de planejamento deve assegurar a "qualidade" ambiental e social do destino.

(iv) Geração de benefícios diretos à população local. Tais iniciativas devem assegurar que os recursos advindos do turismo sejam reaplicados em projetos de meIhoria de qualidade de vida da própria população.

(v) Afirmação cultural e interculturalidade. A valorização da cultura assume importância não como à configuração de um "produto", mas com o objetivo de afirmação de identidade e pertencimento. O intercâmbio de "quem está" e "quem vem" propicia a relação local-global e a prática da interculturalidade.

(vi) $O$ "encontro" como condição essencial. $O$ "encontro" entre identidades assume o sentido de compartilhamento e aprendizagem mútua. Neste sentido, atores locais e turistas são, simultaneamente, agentes, sujeitos e objetos do processo, estabelecendo uma relação de troca, interação, descoberta e retroalimentação.

O TBC integra atividades econômicas de serviços de hospedagem, alimentação e lazer que, a priori, não o diferencia dos demais segmentos turísticos. Seu diferencial recai justamente no entendimento da atividade turística como um subsistema interconectado com outros subsistemas, como educação, saúde e meio ambiente. Neste sentido, o turismo comunitário não se centra somente na atividade turística, representando uma proposta de desenvolvimento territorial sustentável que abrange diversas dimensões - política, cultural, econômica, humana - da vida em sociedade (SAMPAIO; CORIOLANO, 2009).

A reflexão entre as práticas turísticas, em um primeiro momento, nos conduz ao confrontamento de duas realidades distintas: de um lado, os megaempreendimentos autárquicos, isolados e sem relações vinculantes com as comunidades do território onde estão situados; de outro, os empreendimentos de base comunitária, com sua proposta de reverter os benefícios advindos da atividade turística para as comunidades situacionalmente afetadas. A realidade, entretanto, não é composta apenas por duas cores, e sim de uma policromia e tons variados (BURSZTYN et al., 2009).

Reconhecer o valor das experiências do turismo comunitário não deve ser confundido como uma simples apologia aos empreendimentos de pequena escala. $\mathrm{Na}$ tentativa de não cair na vala comum do reducionismo e superficialidade analítica, Bursztyn et al. (2009) tecem algumas considerações: (i) As experiências de TBC bem 
Turismo de Base Comunitária (TBC): elementos chaves para aferir seu desempenho na perspectiva da sustentabilidade

sucedidas não podem ser interpretadas como passíveis de reaplicação em outras localidades e contextos. Tal atitude faria do desenvolvimento situado um objeto de reprodução seriada, ou seja, uma contradição nos próprios termos da questão. (ii) $O$ TBC deve ser encarado em uma perspectiva possibilista e não determinista e prescritiva para o desenvolvimento situado e o turismo. Não podemos interpretá-lo como um modelo estanque, com uma configuração fixa e capaz de atender toda e qualquer realidade. (iii) Deve-se, ainda, reconhecer que iniciativas de TBC não estão isentas de influências externas, divergências internas e conflitos de interesse.

\section{TBC no contexto brasileiro}

Uma pesquisa coordenada por Sansolo e Bursztyn (2009), com 25 representantes de iniciativas brasileiras de turismo de base comunitária, realizada em maio de 2008, durante o II Seminário Internacional de Turismo Sustentável, possibilitou o levantamento e sistematização de algumas informações acerca do desenvolvimento do TBC no Brasil. A maior parte das experiências localiza-se na região nordeste do Brasil, nos estados do Ceará, Rio Grande do Norte, Paraíba e Pernambuco. Destacamse, a seguir, alguns resultados do universo pesquisado:

- O TBC ocorre em pequenas comunidades, assentadas em povoados, aldeias e vilas. Não há referência, nos casos analisados, de experiências envolvendo um município como um todo;

- $80 \%$ das iniciativas ocorrem nas proximidades, no interior ou contêm áreas protegidas, seja em Unidades de Conservação de Proteção Integral ou de Uso Sustentável e Áreas de Preservação Permanente (APP);

- As experiências apresentam uma diversidade de atrativos naturais, culturais e convivenciais. A água destaca-se como um grande atrativo. A balneabilidade de rios e praias, entretanto, pode ser comprometida. Dados apontam que em 2003 apenas $62,9 \%$ da população nordestina foi atendida por abastecimento de água tratada, e somente $34,6 \%$ do esgoto gerado na região é tratado. Tal realidade demonstra que a necessidade de investimento em infraestrutura básica é urgente;

- Ao contrário do turismo convencional, e sua produção de espaços segregados para o turista e para os moradores, a essência do TBC se expressa no território. No turismo comunitário não há sobreposição de territorialidades, turista e comunidade dividem o mesmo lugar, e este representa um espaço de encontro e convivencialidade;

- Em grande parte das iniciativas, as comunidades contaram com apoio externo, normalmente de ONGs e universidades, para a realização do planejamento, estruturação e operação do turismo. Por meio de suporte técnico e apoio financeiro, ONGs nacionais e internacionais assumem um papel fundamental na inserção das comunidades na prática do turismo;

- As formas de propriedade e modo de gestão dos empreendimentos são varia- 
das. Inclui os empreendimentos comunitários geridos por cooperativa e a organização familiar;

- Todas as iniciativas apresentaram "atividades de planejamento" do turismo de base comunitária. A frequência das reuniões, entretanto, varia de encontros semanais até anuais. O formato dos encontros é diverso, em alguns casos envolvem apenas as lideranças formais, em outros, o processo é mais aberto, contando com a participação de lideranças informais, membros da comunidade e até pessoas externas à localidade;

- Em nenhum dos casos o turismo é a única atividade e, muitas vezes, nem a mais importante enquanto atividade econômica. No entanto, o turismo tem representado um apoio ao fortalecimento da autoestima dessas comunidades e um meio de apoio às suas lutas.

No contexto das experiências brasileiras, dois elementos comuns tem se destacado como base nas iniciativas de relativo sucesso. Por um lado, o forte componente de uma afirmação identidária de comunidades enraizadas em sítios simbólicos de pertencimento, e, por outro, o movimento de ativa resistência contra as mais usuais formas de desenvolvimento do turismo (BURSZTYN et al., 2009). Outro elemento marcante refere-se ao caráter da solidariedade. A solidariedade está expressa não apenas dentro da comunidade, por meio da organização de empreendimentos coletivos, mas também entre diferentes iniciativas, que se organizam em redes para se ajudarem mutuamente (LTDS, 2011).

O comprometimento ativo de atores locais também representa uma característica comum nas iniciativas de base comunitária. Em muitos casos, o TBC surge em um contexto onde as comunidades já estão mobilizadas em outras frentes de resistência, como na luta pela posse da terra e pelo direito ao uso sustentável dos recursos naturais. No litoral cearense, por exemplo, a problemática do uso da terra é fundamental para se compreender o processo de formação do TBC - a luta pelo território é o ponto de partida para a organização comunitária. Neste sentido, o turismo comunitário acaba por representar "um meio a mais" - dando voz, força e capacidade articuladora, inclusive com agentes externos, para estas lutas. É como ressalta Bartholo (2009, p.51), "o turismo não é afirmado como elemento identitário no movimento de resistência das comunidades, e sim um meio para dar visibilidade aos conflitos dos modos de vida tradicionais com a chegada da modernidade".

A mobilização das comunidades, em torno de um interesse comum, fornece a base para uma coesão fortalecedora do sentido de comunidade. Segundo Jeffrey Weeks (apud Bauman, 2003, p.91), "o mais forte sentido de comunidade costuma vir dos grupos que percebem as premissas de sua existência coletiva ameaçadas e por isso constroem uma comunidade de identidade que Ihes dá uma sensação de resistência e poder (...)".

Essa face ideológica e militante do TBC é confirmada por Sansolo e Bursztyn 
Turismo de Base Comunitária (TBC): elementos chaves para aferir seu desempenho na perspectiva da sustentabilidade

(2009) em suas averiguações empíricas. Segundo os autores, as iniciativas de turismo comunitário têm em comum as lutas sociais, como a conservação dos recursos naturais - base da subsistência de diversas comunidades - a luta pela terra, pelo direito à memória cultural e por uma educação digna.

\section{Elementos chaves do TBC: base para um sistema de indicadores de desempe- nho na perspectiva da sustentabilidade}

Embora se reconheça que as iniciativas de TBC, dentro de um espectro micro, apresentem características peculiares, considera-se relevante delinear os elementos que podem ser vistos por uma ótica comum em um aspecto macro. Os elementos chaves, aqui propostos, servirão como base para a construção de um instrumento de avaliação de desempenho das experiências de TBC. Tendo em vista a revisão conceitual realizada, emergem os seguintes elementos a serem considerados:

- Dominialidade: refere-se ao grau de domínio da comunidade sobre os aspectos de organização, controle, propriedade e gestão da atividade turística;

- Interculturalidade: relaciona-se com o intercâmbio cultural e a troca de referências e experiências estabelecidas entre os turistas e a comunidade local;

- Organização Social: almeja identificar o modelo e processo de gestão comunitária consolidada em torno do TBC, além de sua interação com o ambiente externo, por meio da participação em redes, comitês, conselhos etc.;

- Repartição de benefícios: refere-se à existência de mecanismos de distribuição de renda e de investimentos, de modo includente, em projetos beneficiando a comunidade resultante da atividade turística;

- Integração econômica: evidencia a integração do turismo com as atividades econômicas tradicionais, identificando os novos arranjos produtivos locais surgidos a partir do seu advento;

- Gestão dos bens comuns: relaciona-se com as instituições internas e articulações externas promovidas pelas iniciativas comunitárias na gestão e salvaguarda dos bens comuns. Ressalta-se que as experiências de TBC são reconhecidas pela alta capacidade de manejo e defesa dos recursos naturais;

\section{Conclusão}

Este artigo buscou propor um conjunto de elementos chaves do TBC a serem utilizados, futururamente, como base para a construção de indicadores para aferição do desempenho de experiências de TBC dentro da perspectiva da sustentabilidade. Isso foi realizado a partir de uma extensa revisão da literatura acerca do tema, ampliando o espectro para noções advindas da academia, de entes governamentais, de terceiro setor e de experiências concretas e emblemáticas de TBC.

Foi possível evidenciar que o componente da organização social é o mais evidente nas conceituações, sendo o mais recorrente naquelas analisadas. $\mathrm{O}$ fundamen- 
to do protagonismo das comunidades na gestão do turismo é o pilar mais forte do TBC. Segue-se a ele a noção de integração de aspectos ambientais e culturais à oferta turística e a resignificação dos encontros e das trocas entre turistas e comunidade receptora. Também com relevância, surge a necessidade de repartição de benefícios entre os membros do grupo. E, com menos ênfase, quase que em um plano secundário, emergem aspectos econômicos e comerciais.

A partir desta análise, 6 foram os elementos chaves selecionados para compor a matriz preliminar que será detalhada em indicadores de desempenho para o TBC: dominialidade, interculturalidade, organização social, repartição de benefícios, integração econômica e gestão do bem comum.

A inovação da abordagem aqui proposta, enraizada e nascida a partir dos conceitos de TBC, está na proposição de elementos chaves ligados às noções inerentes ao TBC, em lugar de importar critérios de outros tipos de iniciativa para avaliá-lo.

Como próximos passos estão previstos: a participação de especialistas na validação dos elementos e no detalhamento dos indicadores, a aplicação piloto de avaliações in loco, a revisão das avaliações por especialistas a fim de atribuir pesos aos indicadores para a composição final do sistema de indicadores, e quiçá um índice de desempenho do TBC, à luz da sustentabilidade.

\section{Referências bibliográficas}

BARTHOLO, R. "Sobre o sentido da proximidade: implicações para um turismo situado de base comunitária”, in: BARTHOLO, R., SANSOLO, D.G, BURSZTYN, I. (Orgs.). Turismo de base comunitária: Diversidade de olhares e experiências brasileiras. Rio de Janeiro (RJ): Letra e Imagem, 2009. p. 45 - 54.

BAUMAN, Z. Comunidade. Rio de Janeiro: Jorge Zahar, 2003.

BRASIL, Ministério do Turismo. Dinâmica e Diversidade do Turismo de Base Comunitária: desafio para a formulação de política pública. Brasília, Ministério do Turismo, 2010.

BURSZTYN, I.; BARTHOLO, R.; DELAMARO, M. Turismo para quem? Sobre caminhos de desenvolvimento e alternativas para o turismo no Brasil. In: BARTHOLO, R., SANSOLO, D.G, BURSZTYN, I. (Orgs.). Turismo de base comunitária: Diversidade de olhares e experiências brasileiras. Rio de Janeiro: Letra e Imagem, 2009. p.76-91.

CLARKE, J. A. Framework of Approaches to Sustainable Tourism. Journal of Sustainable Tourism, v.5, n.3, 1997. p. 224 - 233.

HIWASAKI, L. Comunity-based tourism: A pathway to sustainability for Japan`s protected areas. Society and Natural Resources, vol. 19, 2006. p. $133-143$.

IRVING, M. A. Reinventando a reflexão sobre turismo de base comunitária - inovar é possível? In: BARTHOLO, R.; SANSOLO, D.G.; BURSZTYN, I. (Orgs.). Turismo de base comunitária: Diversidade de olhares e experiências brasileiras. Rio de Janeiro: Letra e Imagem, 2009. p. 108 - 119. 
Turismo de Base Comunitária (TBC): elementos chaves para aferir seu desempenho na perspectiva da sustentabilidade

LTDS, Laboratório de Tecnologia e Desenvolvimento Social. Relatório Técnico: Marco Referencial Teórico para o Turismo de Base Comunitária. Rio de Janeiro, PEP, COPPE/ UFRJ, 2011.

MALDONADO, C. O turismo rural comunitário na América Latina: gênesis, características e políticas. In: BARTHOLO, R.; SANSOLO, D.G.; BURSZTYN, I. (Orgs.). Turismo de base comunitária: Diversidade de olhares e experiências brasileiras. Rio de Janeiro: Letra e Imagem, 2009. p. 25 - 44.

SAMPAIO, C. A. C.; CORIOLANO, L. N. Dialogando com experiências vivenciadas em Marraquech e America Latina para compreensão do turismo comunitário e solidário. Revista Brasileira de Pesquisa em Turismo. Vol. 3, o․ 1, 2009. p. 4-24.

SAMPAIO, C. A. C. LESAMA, M.F. ; ARAUJO, J.R. ; OYARZÚN, E.M. Perspectiva do turismo comunitário, solidário e sustentável. In: SAMPAIO, C. A. C.; HENRIQUEZ, C.; MANSUR, C. (Orgs.). Turismo comunitário, solidário e sustentável: da crítica às ideias e das ideias à prática. Blumenau: Edifurb, 2011. p. 23 - 30.

SANSOLO, D.; BURSZTYN, I. Turismo de base comunitária: potencialidade no espaço rural brasileiro. In: BARTHOLO, R.; SANSOLO, D. G.; BURSZTYN, I. (Orgs.). Turismo de base comunitária: Diversidade de olhares e experiências brasileiras. Rio de Janeiro: Letra e Imagem, 2009. p. 142 - 161.

WWF-INTERNACIONAL. Guidelines for community-based ecotourism development. Disponível em: http://www.panda.org/downloads/policy/guidelinesen.pdf. Julho de 2001. Acesso em 20/05/10.

Nathália Hallack Fabrino: CDS - Universidade de Brasília, Brasília, DF, Brasil.

Email: nathaliahf@ig.com.br

Link para o currículo Lattes: http://lattes.cnpq.br/7727933058081167

Helena Araújo Costa: Dep. Administração, Universidade de Brasília, Brasília, DF, Brasil. Email: helenacosta@unb.br

Link para o currículo Lattes: http://lattes.cnpq.br/4746934995834841

Elimar Pinheiro do Nascimento: CDS - Universidade de Brasília, Brasília, DF, Brasil. Email: elimarcds@gmail.com

Link para o currículo Lattes: http://lattes.cnpq.br/5290901839648752

Data de submissão: 30 de junho de 2012

Data de recebimento de correções: 17 de agosto de 2012

Data do aceite: 17 de agosto de 2012

Avaliado anonimamente 